\title{
A snapshot of the ongoing clinical research on COVID-19
}

\section{[version 1; peer review: 2 approved]}

\section{Daniele Piovani ${ }^{1,2^{*}}$, Claudia Pansieri ${ }^{1,2^{*}}$, Laurent Peyrin-Biroulet ${ }^{3}$, Silvio Danese ${ }^{1,2}$, Stefanos Bonovas (iD) 1,2}

\footnotetext{
${ }^{1}$ Department of Biomedical Sciences, Humanitas University, Pieve Emanuele, Milano, 20090, Italy

${ }^{2}$ Humanitas Clinical and Research Center - IRCCS, Rozzano, Milan, 20089, Italy

${ }^{3}$ Nancy University Hospital, University of Lorraine, Vandoeuvre-lès-Nancy, France

* Equal contributors
}

\section{V1 First published: 18 May 2020, 9:373 \\ https://doi.org/10.12688/f1000research.23843.1}

Latest published: 18 May 2020, 9:373

https://doi.org/10.12688/f1000research.23843.1

\section{Abstract}

The pandemic of coronavirus disease 2019 (COVID-19) presents an unprecedented challenge to rapidly develop new diagnostic, preventive and therapeutic strategies. Currently, thousands of new COVID-19 patients are quickly enrolled in clinical studies. We aimed to investigate the characteristics of the COVID-19 studies registered in ClinicalTrials.gov and report the extent to which they have incorporated features that are desirable for generating high-quality evidence.

On April 28, 2020, a total of 945 studies on COVID-19 have been registered in ClinicalTrials.gov; 586 studies are interventional (62.0\%), the most frequent allocation scheme is the parallel group assignment $(437 ; 74.6 \%)$, they are open-label and the most common primary purpose is the research on treatment.

Too many of the ongoing interventional studies have a small expected sample size and may not generate credible evidence at completion.

This might lead to a delayed recognition of effective therapies that are urgently needed, and a waste of time and resources. In the COVID-19 pandemic era, it is crucial that the adoption of new diagnostic, preventive and therapeutic strategies is based upon evidence coming from well-designed, adequately powered and carefully conducted clinical trials.

Keywords

SARS-CoV-2, 2019-nCoV, 2019 novel coronavirus, severe acute respiratory syndrome coronavirus 2, Covid-19

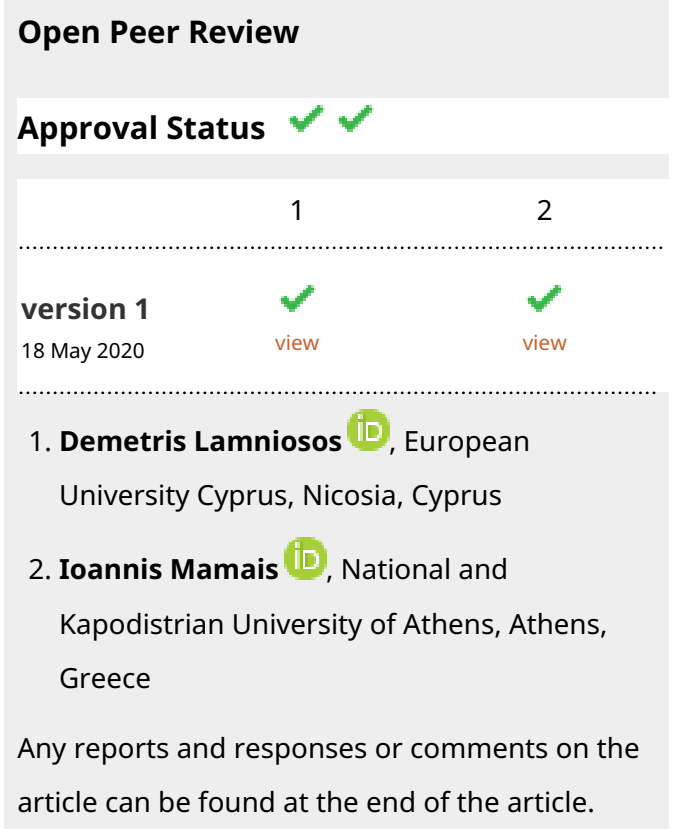

article can be found at the end of the article. 


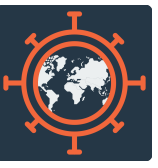

This article is included in the Emerging Diseases

and Outbreaks gateway.

collection.

\section{Corresponding author: Stefanos Bonovas (sbonovas@gmail.com)}

Author roles: Piovani D: Conceptualization, Data Curation, Formal Analysis, Investigation, Methodology, Validation, Writing - Original Draft Preparation, Writing - Review \& Editing; Pansieri C: Conceptualization, Data Curation, Formal Analysis, Investigation, Methodology, Validation, Writing - Original Draft Preparation, Writing - Review \& Editing; Peyrin-Biroulet L: Conceptualization, Methodology,

Supervision, Writing - Original Draft Preparation, Writing - Review \& Editing; Danese S: Conceptualization, Methodology, Supervision, Writing - Original Draft Preparation, Writing - Review \& Editing; Bonovas S: Conceptualization, Data Curation, Investigation, Methodology, Project Administration, Supervision, Validation, Writing - Original Draft Preparation, Writing - Review \& Editing

Competing interests: No competing interests were disclosed.

Grant information: The author(s) declared that no grants were involved in supporting this work.

Copyright: @ 2020 Piovani D et al. This is an open access article distributed under the terms of the Creative Commons Attribution License, which permits unrestricted use, distribution, and reproduction in any medium, provided the original work is properly cited.

How to cite this article: Piovani $D$, Pansieri $C$, Peyrin-Biroulet $L$ et al. A snapshot of the ongoing clinical research on COVID-19 [version 1; peer review: 2 approved] F1000Research 2020, 9:373 https://doi.org/10.12688/f1000research.23843.1

First published: 18 May 2020, 9:373 https://doi.org/10.12688/f1000research.23843.1 


\section{Introduction}

The pandemic of coronavirus disease 2019 (COVID-19) caused by the novel severe acute respiratory syndrome coronavirus 2 (SARS-CoV-2) presents an unprecedented challenge to rapidly develop new diagnostic, preventive and therapeutic strategies ${ }^{1}$. Currently, thousands of new COVID-19 patients present for care every day, and many are quickly enrolled in clinical studies. We aimed to investigate the characteristics of the COVID-19 studies registered in ClinicalTrials.gov ${ }^{2}$, and report the extent to which they have incorporated features that are desirable for generating high-quality evidence.

\section{Methods}

We investigated the ClinicalTrials.gov website on April 28, 2020, using the search term: SARS-CoV-2 OR 2019-nCoV OR 2019 novel coronavirus OR severe acute respiratory syndrome coronavirus 2 OR Covid-19. No restrictions were applied. No screening of trials was performed; all results were included regardless of their content.

Stata 15.0 (Stata Corp., College Station, TX, USA) was used for the analysis of study characteristics.

\section{Results}

A total of 945 studies on COVID-19 have been registered in ClinicalTrials.gov up to April 29, 2020; 586 studies are interventional $(62.0 \%)$, and 435 of them $(74.2 \%)$ are randomized. Among interventional studies, the most frequent allocation scheme is the parallel group assignment $(437 ; 74.6 \%)$, followed by single group $(111 ; 18.9 \%]$, sequential $(18 ; 3.1 \%)$, factorial (9; $1.5 \%)$, and cross-over assignment $(11 ; 1.9 \%)$. The majority of the clinical trials are open-label (no masking, 338 [57.7\%]); however, $57(9.7 \%)$ trials are double-blinded, $41(7.0 \%)$ triple-blinded, $90(15.4 \%)$ quadruple-blinded, and $60(10.2 \%)$ single-blinded. Among observational studies, cohort (222; 64.3\%) is the most common study design (Table 1).

Table 1. Characteristics of COVID-19 studies registered in ClinicalTrials.gov $(n=945)$.

\begin{tabular}{|l|c|}
\hline Study type & N (\%) \\
\hline Study design ( $\mathrm{n}=945)$ & $586(62.0)$ \\
\hline Interventional & $345(36.5)$ \\
\hline Observational & $14(1.5)$ \\
\hline Expanded access & \\
\hline Recruitment status ( $\mathrm{n=945)}$ & $453(47.9)$ \\
\hline Recruiting or enrolling by invitation & $414(43.8)$ \\
\hline Not yet recruiting & $24(2.5)$ \\
\hline Active, not recruiting & $27(2.9)$ \\
\hline Completed & $13(1.4)$ \\
\hline Withdrawn, terminated or suspended & $13(1.4)$ \\
\hline Available & \\
\hline Intervention type $(\mathrm{n}=945)$ & \\
\hline
\end{tabular}

\begin{tabular}{|c|c|}
\hline Study type & $\mathbf{N}(\%)$ \\
\hline Drug & 405 (42.9) \\
\hline $\begin{array}{l}\text { Biological (cells, blood sampling, } \\
\text { etc) }\end{array}$ & $74(7.8)$ \\
\hline Diagnostic test & $60(6.3)$ \\
\hline Device & $44(4.7)$ \\
\hline Procedure & $18(1.9)$ \\
\hline Behavioral & $20(2.1)$ \\
\hline Dietary supplement & $9(1.0)$ \\
\hline Other/Unknown & 315 (33.3) \\
\hline \multicolumn{2}{|l|}{ Target age $(n=945)$} \\
\hline Any age & $165(17.5)$ \\
\hline Child (<18 y) & $5(0.5)$ \\
\hline Child and adult (<65 y) & $8(0.8)$ \\
\hline Adult (18-65 y) & $35(3.7)$ \\
\hline Adult and elderly ( $\geq 18 \mathrm{y}$ ) & $720(76.2)$ \\
\hline Elderly ( $\geq 66$ y) & $12(1.3)$ \\
\hline \multicolumn{2}{|l|}{ Funding $(n=945)$} \\
\hline $\mathrm{NIH}$ or federal & $13(1.4)$ \\
\hline Industry & $82(8.7)$ \\
\hline Industry plus other & $63(6.7)$ \\
\hline $\begin{array}{l}\text { Other (organizations, universities, } \\
\text { individuals) }\end{array}$ & 787 (83.2) \\
\hline Expected trial size $(n=931)$ & $200(66-504)$ \\
\hline $0-100$ & $344(37.0)$ \\
\hline $101-1000$ & $439(47.1)$ \\
\hline$>1000$ & $148(15.9)$ \\
\hline $\begin{array}{l}\text { Interventional }(\mathrm{n}=586) \text { [median } \\
(\text { IQR)] }\end{array}$ & $150(52-420)$ \\
\hline $\begin{array}{l}\text { Observational }(n=345) \text { [median } \\
(\text { IQR)] }\end{array}$ & $300(100-1,000)$ \\
\hline \multicolumn{2}{|l|}{ Study results ( $n=945)$} \\
\hline Not available & $945(100)$ \\
\hline \multicolumn{2}{|l|}{ Interventional studies $(n=586)$} \\
\hline \multicolumn{2}{|l|}{ Study phase $(n=586)$} \\
\hline Phase $0,1,1 / 2$ & $62(10.6)$ \\
\hline Phase 2, 2/3 & $212(36.2)$ \\
\hline Phase 3, 4 & $165(28.1)$ \\
\hline Not applicable & $147(25.1)$ \\
\hline \multicolumn{2}{|l|}{ Model $(n=586)$} \\
\hline Parallel assignment & $437(74.6)$ \\
\hline Single group assignment & $111(18.9)$ \\
\hline Sequential & $18(3.1)$ \\
\hline Factorial assignment & $9(1.5)$ \\
\hline Crossover assignment & $11(1.9)$ \\
\hline Masking $(n=586)$ & \\
\hline
\end{tabular}




\begin{tabular}{|l|c|}
\hline Study type & N (\%) \\
\hline Open label or no masking & $338(57.7)$ \\
\hline Single-blind & $60(10.2)$ \\
\hline Double-blind & $57(9.7)$ \\
\hline Triple-blind & $41(7.0)$ \\
\hline Quadruple-blind & $90(15.4)$ \\
\hline Study allocation (n=586) & \\
\hline Randomized & $435(74.2)$ \\
\hline Non-randomized & $53(9.1)$ \\
\hline Unknown/missing & $98(16.7)$ \\
\hline Observational studies (n=345) & \\
\hline Observational model $(n=345)$ & \\
\hline Cohort & $222(64.3)$ \\
\hline Case-control & $34(9.9)$ \\
\hline Case-only & $45(13.0)$ \\
\hline Ecologic or community & $11(3.2)$ \\
\hline Other & $33(9.6)$ \\
\hline Time perspective $(n=345)$ & $230(66.7)$ \\
\hline Prospective & $58(16.8)$ \\
\hline Retrospective & $31(9.0)$ \\
\hline Cross-sectional & $26(7.5)$ \\
\hline Other & \\
\hline
\end{tabular}

Most studies target adult or elderly participants, while 178 (18.8\%) enroll children, with only five $(0.5 \%)$ recruiting exclusively children. Median expected study size is 200 (interquartile range, 66-504), although sample sizes vary from $\leq 100(344 ; 37.0 \%)$ to $>1,000$ individuals $(148 ; 15.9 \%)$. Overall, only 27 of 945 studies $(2.9 \%)$ have completed recruitment, 453 (47.9\%) are actively recruiting subjects, while a large number of studies $(414 ; 43.8 \%)$ are not yet actively recruiting participants. Most of the studies are conducted in Europe $(n=327)$, North America $(n=217$, of which 186 in the US), East Asia $(n=102)$, Africa $(n=27)$, and in South America $(n=26)$. No study has reported results yet.

Among the interventional studies, the most common primary purpose is the research on treatment $(441 ; 75.3 \%)$, followed by prevention $(79 ; 13.5 \%)$, supportive care studies $(22 ; 3.8 \%)$, and diagnostic investigations $(17 ; 2.9 \%)$. Regarding the drugs under scrutiny, hydroxychloroquine $(110 ; 28.6 \%)$, azithromycin (38; $9.9 \%)$, lopinavir/ritonavir $(24 ; 6.2 \%)$, interferon- $\alpha$ and $-\beta(24$; $6.2 \%)$, glucocorticoids $(22 ; 5.7 \%)$, chloroquine $(14 ; 3.6 \%)$, favipiravir $(10 ; 2.6 \%)$, remdesivir $(8 ; 2.1 \%)$, tocilizumab (21; 5.5\%), anti-SARS-CoV-2 immunoglobulins $(15 ; 3.9 \%)$ and sarilumab $(9 ; 2.3 \%)$ account for the majority of interventional studies. Additional details are featured in Table 2.

\section{Table 2. Characteristics of COVID-19 interventional studies registered in ClinicalTrials.gov $(n=586)$.}

\begin{tabular}{|c|c|}
\hline Study type & No. (\%) \\
\hline \multicolumn{2}{|l|}{ Primary purpose $(n=586)$} \\
\hline Treatment & $441(75.3)$ \\
\hline Prevention & 79 (13.5) \\
\hline Supportive care & $22(3.8)$ \\
\hline Diagnostic & $17(2.9)$ \\
\hline Other & $13(2.2)$ \\
\hline Screening & $5(0.8)$ \\
\hline Basic science & $5(0.8)$ \\
\hline Health services research & $4(0.7)$ \\
\hline \multicolumn{2}{|l|}{ Drugs $(n=385)$} \\
\hline \multicolumn{2}{|l|}{ Repurposed drugs } \\
\hline Hydroxychloroquine & $110(28.6)$ \\
\hline Azithromycin & $38(9.9)$ \\
\hline Lopinavir/Ritonavir & $24(6.2)$ \\
\hline Glucocorticoids & $22(5.7)$ \\
\hline Interferon- $\alpha$ and $-\beta$ & $24(6.2)$ \\
\hline Chloroquine & $14(3.6)$ \\
\hline Nitazoxanide & $8(2.1)$ \\
\hline Camostat & $4(1.0)$ \\
\hline Oseltamivir & $4(1.0)$ \\
\hline Ribavirin & $1(0.3)$ \\
\hline \multicolumn{2}{|l|}{ Investigational agents } \\
\hline Favipiravir & $10(2.6)$ \\
\hline Remdesivir & $8(2.1)$ \\
\hline \multicolumn{2}{|l|}{ Adjunctive therapies } \\
\hline Tocilizumab & $21(5.5)$ \\
\hline $\begin{array}{l}\text { Anti SARS-CoV-2 } \\
\text { immunoglobulins }\end{array}$ & $15(3.9)$ \\
\hline Sarilumab & $9(2.3)$ \\
\hline
\end{tabular}

\section{Discussion}

Our survey presents the current COVID-19 clinical research landscape. Several hundreds of clinical studies have been initiated all over the globe, and the number is growing. Most interventional studies incorporate randomisation, which is considered the hallmark of high-quality clinical trials ${ }^{3}$, while more than $40 \%$ are blinded.

Studies are being conducted especially in the most affected areas: Europe and US. The number of COVID-19 cases in low 
to middle-income countries is still relatively low, also reflecting scarce testing, but is expected to rise in the next period. These countries will need more research on organizational measures, and trials on interventions that are affordable and applicable to those settings ${ }^{4}$.

Most studies focus on adults and elderlies, while only few target children, possibly reflecting the observed burden of the disease. Additional effort is needed to ensure that minors are included in COVID-19 clinical research, so that therapeutic decisions are based upon high-quality evidence.

No drug with proven clinical efficacy currently exists for SARS-CoV-2 infection. Despite the absence of solid evidence, several treatments are being currently used in clinical practice in several countries, with sometimes disastrous consequences ${ }^{5}$. Too many of the ongoing interventional studies have a small expected sample size, and may not generate credible evidence at completion $^{4}$. This might lead to a delayed recognition of effective therapies that are urgently needed, and a waste of time and resources. In the COVID-19 pandemic era, it is crucial that the adoption of new diagnostic, preventive and therapeutic strategies is based upon evidence coming from well-designed, adequately powered and carefully conducted clinical trials.

\section{Data availability}

The Clinical Trials website can be accessed here: https:// clinicaltrials.gov/
1. Sanders JM, Monogue ML, Jodlowski TZ, et al.: Pharmacologic Treatments for Coronavirus Disease 2019 (COVID-19): A Review. JAMA. 2020. PubMed Abstract | Publisher Full Text

2. ClinicalTrials.gov. 2020; Accessed at 21 April 2020 Reference Source

3. Moher D: CONSORT: an evolving tool to help improve the quality of reports of randomized controlled trials. Consolidated Standards of Reporting Trials. JAMA. 1998; 279(18): 1489-1491. PubMed Abstract | Publisher Full Text
4. COVID-19 Clinical Research Coalition: Global coalition to accelerate COVID-19 clinical research in resource-limited settings. Lancet. 2020; 395(10233): 1322-1325.

PubMed Abstract | Publisher Full Text

5. Owens B: Excitement around hydroxychloroquine for treating COVID-19 causes challenges for rheumatology. Lancet Rheumatol. 2020; 2(5): e257.

PubMed Abstract | Publisher Full Text | Free Full Text 


\section{Open Peer Review}

\section{Current Peer Review Status:}

\section{Version 1}

Reviewer Report 28 May 2020

https://doi.org/10.5256/f1000research.26310.r63547

(C) 2020 Mamais I. This is an open access peer review report distributed under the terms of the Creative Commons Attribution License, which permits unrestricted use, distribution, and reproduction in any medium, provided the original work is properly cited. The author(s) is/are employees of the US Government and therefore domestic copyright protection in USA does not apply to this work. The work may be protected under the copyright laws of other jurisdictions when used in those jurisdictions.

\section{Ioannis Mamais}

Department of Hygiene, Epidemiology and Medical Statistics, Medical School, National and Kapodistrian University of Athens, Athens, Greece

I have read it through, and it seems to be an interesting brief report.

Some comments below:

$74.2 \%$ of those studies are mention as "Randomized" and $40 \%$ as blinded, from researchers. Authors of this brief report can "discuss" those numbers and prepare readers that most of those may have a high risk of bias (maybe with no control group, or bias arising from the randomisation process, etc).

"Additional effort is needed to ensure that minors are included in COVID-19 clinical research, so that therapeutic decisions are based upon high-quality evidence". I am not very sure if it is necessary to discuss this in the brief report

Is the work clearly and accurately presented and does it cite the current literature? Yes

Is the study design appropriate and is the work technically sound? Yes

Are sufficient details of methods and analysis provided to allow replication by others? Partly

If applicable, is the statistical analysis and its interpretation appropriate? Not applicable 
Are all the source data underlying the results available to ensure full reproducibility? Yes

Are the conclusions drawn adequately supported by the results?

Yes

Competing Interests: No competing interests were disclosed.

Reviewer Expertise: Molecular Epidemiology

I confirm that I have read this submission and believe that I have an appropriate level of expertise to confirm that it is of an acceptable scientific standard.

Reviewer Report 26 May 2020

https://doi.org/10.5256/f1000research.26310.r63548

(C) 2020 Lamniosos D. This is an open access peer review report distributed under the terms of the Creative Commons Attribution License, which permits unrestricted use, distribution, and reproduction in any medium, provided the original work is properly cited.

\section{Demetris Lamniosos}

Department of Health Sciences, School of Sciences, European University Cyprus, Nicosia, Cyprus

This brief report is a survey of the current COVID-19 clinical research landscape. The number of clinical studies on COVID-19 is rapidly growing and it is important the investigation of whether these studies are incorporating features that are desirable for generating high-quality evidence. This survey performed this investigation and found that too many of the ongoing interventional studies have a small expected sample size. This might lead to delayed recognition of effective therapies and a waste of time and resources. This important evidence should guide the design of any future clinical study on COVID-19 and the decision of any funding body as well as the approval of any bioethics committee. For this reason, I consider this brief report important for the scientific community.

There are a few minor suggestions for the authors:

Table 1: The presentation of the studies' characteristics will be improved if they are presented separately for interventional and observational studies (particularly for the intervention type and expected study size). In this way, the table will provide more information about the studies' characteristics for each study type (interventional and observational).

Table 1: It will be useful to report the type of randomization (such as blocking and block size).

Is the work clearly and accurately presented and does it cite the current literature? Yes

Is the study design appropriate and is the work technically sound? 
Yes

Are sufficient details of methods and analysis provided to allow replication by others? Yes

If applicable, is the statistical analysis and its interpretation appropriate?

Not applicable

Are all the source data underlying the results available to ensure full reproducibility? Yes

Are the conclusions drawn adequately supported by the results? Yes

Competing Interests: No competing interests were disclosed.

Reviewer Expertise: Epidemiology, Statistics, Research Methods, Public Health

I confirm that I have read this submission and believe that I have an appropriate level of expertise to confirm that it is of an acceptable scientific standard.

The benefits of publishing with F1000Research:

- Your article is published within days, with no editorial bias

- You can publish traditional articles, null/negative results, case reports, data notes and more

- The peer review process is transparent and collaborative

- Your article is indexed in PubMed after passing peer review

- Dedicated customer support at every stage

For pre-submission enquiries, contact research@f1000.com 